\title{
Sustainable Debts and Deficits in Emerging Markets
}

Ashima Goyal

Quantitative Approaches to Public Policy Conference in Honour of Professor T. Krishna Kumar

Held in conjunction with the

Fourth Annual International Conference on Public Policy and Management Indian Institute of Management Bangalore (IIMB)

\section{9-12 August 2009}

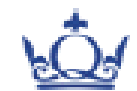

School of Business and Management Queen Mary, University of London London, United Kingdom

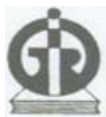

Indira Gandhi Institute of Development Research Mumbai, India

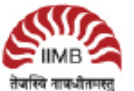

Centre for Public Policy Indian Institute of Management Bangalore, India 


\title{
Sustainable debt and deficits in emerging markets
}

\section{Ashima Goyal ${ }^{*}$}

July 2009

\section{Professor}

\author{
Indira Gandhi Institute of Development Research \\ Gen. Vaidya Marg, Santosh Nagar, \\ Goregaon (E), Mumbai-400 065 \\ ashima@ igidr.ac.in \\ Tel.: +91-22-28416524 Fax: +91-22-28402752 \\ http://www.igidr.ac.in/ ashima
}

\begin{abstract}
Rising fiscal deficits in the context of high debt ratios can trigger a sudden stop or reversal of capital inflows in an emerging market. These features were found together in early currency crises. Countries in these episodes had low private savings rates and low population densities. But higher private savings can compensate for government dissaving and reduce pressure on balance of payments. Second, in high population density emerging markets in a catch-up phase, sustainable debts and deficits may be higher. Analysis of the evolution of government debt shows how debt ratios fall with growth rates. An optimizing model of a small open emerging market economy (SOEME) with dualistic labour markets and two types of consumers, shows debt ratios would tend to be higher in high growth phases in such emerging markets, and the conditions under which fiscal and monetary coordination can occur. The paper concludes with some application to and assessment of Indian debt and deficit ratios.
\end{abstract}

JEL Codes: H63, E62, E52, D90

Key words: Deficits; Debt; Sustainability; Monetary-Fiscal Policy; Emerging Markets

\footnotetext{
${ }^{*}$ Draft written for the conference in honour of Professor Krishna Kumar to be held in Bangalore in August 2009. I thank Srijit Mishra and Sushanta Mallick for the invitation and Reshma Aguiar and Shruti Tripathi for assistance.
} 


\section{Introduction}

Fund managers are trained to be doubtful about an emerging market with rising fiscal deficits and high debts ratios. But we argue risk assessments must be context sensitive. The Indian government's fiscal deficit rose sharply in 2008-09 exceeding its targeted value by about 4 percent, although before that the government was on target to achieve the steady reduction in deficits as mandated by the 2003 FRBM Act. The lapse was partly driven by oil shock subsidies, unbudgeted pay commission awards and poor expenditure management but it was required in a situation of dire external demand shocks, and a fear cum earlier domestic monetary tightening led decline in demand, which reduced output to much below potential.

To associate high Indian deficit ratios with higher risk is to extrapolate unconditionally from past crises in Latin American countries where these features were found together. These countries had low savings rates and low population densities. In India higher private savings compensates for government dissaving. In this paper we show how high private saving reduces the current account deficit. Therefore twin deficits that provoke outflows become unlikely.

Fiscal stimuli have contributed to making India one of the brighter spots in a dismal globe. But there are fears the government may not have the capacity to reverse rising deficits, and with debt ratios already at 80 percent, an unsustainable rise in debt may result.

But the second exercise in this paper shows how high growth rates in high population density emerging markets in a catch-up phase can be expected to reduce debt ratios. Examining India's dynamic government budget constraint shows a decrease in debt in high growth periods. But in the post 2003 phase this was less than feasible, despite the notification of the FRBM. 
Third, introducing the dynamic debt equation in a DSGE open economy model used for monetary policy helps to understand these outcomes, and derive results for monetary and fiscal policy and their interaction. The key feature of the model making it relevant for the analysis of populous emerging markets is that it distinguishes between two types of consumers and suppliers of labour. It is therefore able to capture the effects of transition as the labour share in the more productive occupations rises, and to model the typical shocks in emerging markets. In response to shocks to subsistence consumption the model throws up a large increase in debt. The rise is more if debt levels are already high, and if there is higher growth. This is the exact Indian fiscal response during the high growth period and during the financial crisis. Monetary accommodation reduces debt levels but can increase instability if there is a permanent rise in government expenditure. Higher growth does reduce per capita debt levels. As labour share in productive occupations rises, debt ratios would fall. Backwardness in technology, infrastructure and education reduce natural output, but the correct fiscal interventions can increase it.

Implications for current Indian macroeconomic policy, explored in the final section of the paper, are revamping the Fiscal Responsibility and Budget Management (FRBM) legislation to emphasize expenditure management, shifting government expenditure to components that raise growth, rather than focusing on deficits. With a better FRBM ensuring the expansion in government expenditure is restricted to the short-term, and growth oriented fiscal consolidation takes place in the long-term, monetary policy can safely support an expansion of government expenditure in the short-term.

\section{Twin Deficits and Debt}

The balance of payments is the record of a country's foreign transactions in an open economy. Assume, for the time being, there is no income from abroad and no government, then the basic macroeconomic income equal to expenditure identity is $\mathrm{Y}=$ $\mathrm{C}+\mathrm{I}+\mathrm{X}-\mathrm{M}$. Net exports are also the trade surplus, in this case equal to the current account surplus of the balance of payments, $C A$. Thus $C A=X-M=N X$. Substituting savings, $S$, for $\mathrm{Y}-\mathrm{C}$, in the basic identity, gives $\mathrm{S}-\mathrm{I}=\mathrm{X}-\mathrm{M}$. Thus the $\mathrm{CA}$ is also equal to $\mathrm{S}-\mathrm{I}$. The popular conception of CA is identified with the net exports of goods and services. But 
this derivation makes it clear that the CA depends on macro policies affecting $\mathrm{S}$ and I, and not on trade policies. If domestic savings exceed investment this must be reflected in exports exceeding imports and vice versa. If investment exceeds savings there would be a current account deficit: $\mathrm{CAD}=\mathrm{I}-\mathrm{S}$.

On introducing government, the CAD can be derived as the excess of I over S plus the excess of government expenditure over taxes or the government deficit (GD). From Y-T$\mathrm{C}+\mathrm{T}-\mathrm{G}-\mathrm{I}=\mathrm{X}-\mathrm{M}$, we get $\mathrm{S}=\mathrm{S}^{\mathrm{P}}+\mathrm{T}-\mathrm{G}=\mathrm{I}+\mathrm{NX}$ or $\mathrm{I}=\mathrm{S}^{\mathrm{P}}+\mathrm{S}^{\mathrm{G}}+\mathrm{NM}$. That is:

$$
\mathrm{CAD}=\mathrm{I}-\mathrm{S}^{\mathrm{P}}+\mathrm{GD}
$$

So as government expenditure exceeds taxes, unless I falls or $\mathrm{S}^{\mathrm{P}}$ rises, the CAD will widen. This is the twin deficits hypothesis, where one deficit is expected to lead to the other, so that both can be expected to occur together. But a government deficit need not necessarily imply positive CAD if private savings are high.

$$
\mathrm{S}^{\mathrm{P}}=\mathrm{I}+\mathrm{CA}+\mathrm{G}-\mathrm{T}
$$

In an open economy, private savings can be used for domestic investment, acquiring assets from foreigners and for buying government debt. In many Asian countries a rise in income tends to raise savings more than consumption. In boom times investment may exceed savings but only marginally. For example, the current account deficit, which finances the difference between investment and domestic savings, remained around 1 percent of GDP in India. Capital flows much larger than the current account deficit were accumulated as reserves. With these cushions of domestic and foreign resources available, temporary government dissaving is not threatening.

\section{Evolution of Government Debt}

The other danger from a government deficit is that it adds to government debt. We turn, therefore, to examine the evolution of government debt. Assume a cashless economy in which all government debt consists of riskless one-period nominal debt. Then value at 
issuance rather than at maturity of quantity outstanding of one-period government bonds is, $D_{t}$. This nominal value of public debt changes over time as follows:

$$
D_{t}=\left(1+i_{t-1}\right) D_{t-1}+\left(P_{t} G_{t}-T_{t}\right)
$$

The maturity value of real public debt is:

$$
B_{t} \equiv\left(1+i_{t}\right) D_{t} / P_{t}
$$

Real government purchases are $G_{t}$ and nominal net tax collections are $T_{t}$ so that real tax collections as a ratio to output $\mathrm{Y}_{\mathrm{t}}$ are $\tau \equiv T_{t} / P_{t}$. The real debt to output ratio is $\mathrm{b}_{\mathrm{t}}$. Substituting for $\mathrm{B}_{\mathrm{t}}$ in (3) and dividing by $\mathrm{Y}_{\mathrm{t}}$, the latter can be written as:

$$
\frac{B_{t} P_{t}}{\left(1+i_{t}\right) Y_{t}}=\frac{B_{t-1} P_{t-1}}{Y_{t}}+\frac{P_{t} G_{t}}{Y_{t}}-\frac{T_{t}}{Y_{t}}
$$

This can be transformed into:

$$
\frac{B_{t}}{Y_{t}}=\left(1+i_{t}\right) \frac{B_{t-1}}{Y_{t-1}} \frac{Y_{t-1}}{Y_{t}} \frac{P_{t-1}}{P_{t}}+\frac{G_{t}}{Y_{t}}-\frac{T_{t}}{P_{t} Y_{t}}
$$

And further using $g_{t}=Y_{t} / Y_{t-1}, \pi_{t}=P_{t} / P_{t-1}$ and the approximation $\left(1+i_{t}\right) /\left(1+g_{t}\right)\left(1+\pi_{t}\right)=1+i_{t}-g_{t}-\pi_{t}$.

$$
b_{t}-b_{t-1}=\left(i_{t}-\pi_{t}-g_{t}\right) b_{t-1}+\frac{G_{t}}{Y_{t}}-\tau_{t}
$$

Equation (6) gives the evolution of the real debt ratio. Higher debt increases real debt as interest payments rise, as does the primary deficit ratio $(p d)$ or excess of real government expenditure over taxation as a ratio to output. Therefore high debt levels can imply 
exploding unsustainable debt. Falling real interest rates and rising growth rates effectively reduce government debt. Inflation and growth rates do not effect the nominal value of public debt, $\mathrm{D}_{\mathrm{t}}$, which increases in any year by nominal interest payments on debt plus the $P D, P_{t} G_{t}-T_{t}$. The latter is the non-interest budget deficit, while the fiscal deficit includes interest payments and is the total government borrowing requirement. If the real interest rate equals the rate of growth, the PD ratio alone would add to the debt ratio.

\section{Introducing Fiscal Policy in the SOEME Model}

So far we have considered the effects of fiscal policy on the government debt taking the interest and inflation rate as given. But the latter are determined by monetary policy. So we turn to examine what are the restrictions on fiscal policy, which will allow optimal choice of interest rates in the context of a small open emerging market economy (SOEME), or if the structure of a SOEME gives greater degrees of freedom for policy.

Optimal monetary policy has been derived in dynamic stochastic general equilibrium models with imperfect competition and nominal rigidities ${ }^{1}$, and is found to have substantial effects on real variables. Under monopolistic competition with product diversity individual producers have market power implying output is suboptimally low. This, together with some type of price stickiness, allows monetary policy to have real effects. This framework is promising for the analysis of emerging markets since the rigidities that dominate these markets can be introduced. Optimization over time by consumers, workers and firms can be reduced to simple aggregate demand and supply curves with forward-looking variables. Being derived from basic technology, preferences and market structure, the coefficients of the equations are robust to policy changes, thus meeting the Lucas critique. The policy problem then simplifies to minimization of the deviation of output and inflation from steady-state values subject to these curves.

\footnotetext{
${ }^{1}$ See Clarida et. al (1999) for a survey, and Clarida et. al (2001) for extension to an open economy. Woodford (2003) offers a rigorous treatment of the literature.
} 
Goyal $(2007,2009 a, b)$ adapted the basic model $^{2}$ to make it relevant to analyze monetary policy in emerging markets with a large share of less productive labour in the process of being absorbed into the modern sector. The steady-state full employment assumption of equilibrium models is far from adequate in these markets. At the very least, two types of consumers and workers need to be distinguished in the SOEME - those above subsistence $(\mathrm{R})$, and those at subsistence $(\mathrm{P})$. While the first are able to smooth consumption using international markets, those at subsistence cannot. Their intertemporal elasticity of consumption, productivity and wages are lower and their labor supply elasticity is higher, compared to the first group. All these follow from the key difference- high and low productivity. The product market structure, technology and preferences of $\mathrm{R}$ type consumers are the same across all economies. Productivity shocks differ since emerging markets are in transition stages of applying the new technologies becoming available. $P$ type consumers are assumed to be at a fixed subsistence wage, financed in part by transfers from R types, mediated by the government.

The basic consumption Euler, household labor supply, risk sharing, and firms' profit maximization for each type is derived in the appendix. Given risk sharing only for the $\mathrm{R}$ type, exogenous subsistence level consumption of the $\mathrm{P}$ type, and the aggregate demand supply equality across countries, each of measure unity, it is possible to solve for the terms of trade in terms of endogenous output, $\mathrm{Y}_{\mathrm{t}}$, and exogenous variables, world output, $\mathrm{Y}_{\mathrm{t}}{ }^{*}$ and the consumption of the $\mathrm{P}$ type, $\mathrm{C}_{\mathrm{P}, \mathrm{t}}$ (see appendix). Substituting out the terms of trade, and taking deviations of output from the natural output to write the first order conditions as functions of log output gap and domestic inflation $\pi_{\mathrm{H}}$ then gives the final form of the two aggregate supply (AS) and aggregate demand (AD) equations. The level where marginal cost is at its desired steady-state level defines the natural output $\overline{y_{t}}$. Low productivity, poor infrastructure and other distortions keep the natural output in the SOEME below world levels and convergence to world levels is part of the process of development. Consumer prices, which enter the consumer's maximand are converted into producer or domestic prices using the terms of trade.

\footnotetext{
${ }^{2}$ The basic model followed is Gali and Monacelli (2005) (henceforth GM). Goyal (2007) offers a systematic comparison of results for an emerging market compared to the SOE GM model.
} 
The intertemporal elasticity of consumption is $\left(1 / \sigma_{\mathrm{i}}\right)$, labour supply elasticity $\left(1 / \varphi_{\mathrm{i}}\right)$ with the subscript indicating the R or P type respectively; without the subscript it is the aggregate value. The population share of $R$ is $\eta, 0<\eta<1$. The share of foreign goods, $\alpha$, $0<\alpha<1$. The discount factor is $\beta$, so that $\rho \equiv \beta^{-1}-1$ is the time discount rate; $\mathrm{i}_{\mathrm{t}}$ is the riskless nominal interest rate; $\pi_{t} \equiv p_{t}-p_{t-1}$ is CPI (consumer price index) inflation (with $\mathrm{p}_{\mathrm{t}} \equiv \log \mathrm{P}_{\mathrm{t}}$ ); productivity is $a_{t}$. Lower case letters are logs of the respective variables.

The final form of dynamic aggregate supply is:

$$
\pi_{H, t}=\beta E_{t}\left\{\pi_{H, t+1}\right\}+\kappa_{D} x_{t}
$$

The slope for a SOEME is $\kappa_{D}=\lambda\left(\sigma_{D}+\varphi\right)$, compared to $\lambda(\sigma+\varphi)$ for a closed economy and $\lambda\left(\sigma_{\alpha}+\varphi\right)$ for a SOE, where $\sigma_{\alpha}=\frac{\sigma_{R}}{(1-\alpha)+\varpi \alpha}, \sigma_{D}=\frac{\sigma_{R}}{(\eta(1-\alpha)+\varpi \alpha)}$. Since R in the SOEME are identical to the representative SOE consumer, $\sigma_{\mathrm{R}}$ enters $\sigma_{\alpha}$ and $\sigma_{\mathrm{D}}$. The slope is reduced in an open compared to a closed economy since $\sigma>\sigma_{\mathrm{D}}>\sigma_{\alpha}$, but the slope can be higher in the SOEME compared to a SOE, even though $\varphi$ is lower for the SOEME, since $\sigma_{\mathrm{D}}>\sigma_{\alpha}$. While $\sigma_{\alpha}=1$ if $\sigma_{\mathrm{R}}=1, \sigma_{\mathrm{D}}$ always exceeds unity if $\alpha<1$. Similar results hold for the more general case of $\sigma_{\mathrm{R}} \neq 1$. Since the gap between $\sigma$ and $\sigma_{\mathrm{D}}$ is large and varies with $\eta$ and $\alpha$, the slope for the SOEME remains larger than in the SOE.

The dynamic $\mathrm{AD}$ equation for the SOEME is:

$$
x_{t}=E_{t}\left\{x_{t+1}\right\}-\frac{1}{\sigma_{D}}\left(i_{t}-E_{t}\left\{\pi_{H, t+1}\right\}-\overline{r r}_{t}\right)
$$

Where $\overline{r r}_{t}=\rho-\sigma_{D} \Gamma\left(1-\rho_{a}\right) a_{t}-\sigma_{D}(1-\eta+\Phi) E_{t}\left\{\Delta c_{P, t+1}\right\}+\sigma_{D}(\Theta-\Psi) E_{t}\left\{\Delta y_{t+1}^{*}\right\}$

and

$$
\begin{gathered}
\Theta=\alpha(\varpi-\eta), \quad d=\frac{1}{\sigma_{D}+\varphi}, \Gamma=\frac{(1+\varphi)}{\sigma_{D}+\varphi}, \Psi=\eta\left(\sigma-\sigma_{D}\right) d, \\
\Phi=d\left((1-\eta)\left(\sigma-\sigma_{D}\right)\right)
\end{gathered}
$$


Since $\sigma_{\mathrm{D}}>\sigma_{\alpha}$, the output gap, just like output, is less responsive to the interest rate in the SOEME compared to the SOE, while shocks to subsistence consumption, $c_{P}$, are a new source of shocks to the natural rate in a SOEME. As $\eta$ approaches unity implying the economy has developed the $c_{P}$ term disappears and the equations collapse to those of the SOE.

\section{Government debt}

We now want to add an equation for the response of government debt to a shock that could include change in fiscal policy. Since we are interested in local equilibrium determination it is sufficient to consider fiscal rules that are nearly consistent with a steady state ${ }^{3}$. In a steady state with zero inflation and real disturbances both $\mathrm{B}_{\mathrm{t}}$ and real tax collections $\tau \equiv T_{t} / P_{t}$ are equal to constant values $\bar{\tau}, \bar{B}>0$, and $Y_{t}=\bar{Y}>0, G_{t}=\bar{G} \geq 0$, and $i_{t}=\bar{i} \equiv \beta^{-1}-1>0$. For consistency with the evolution of nominal debt (3), steady-state fiscal values must satisfy $\bar{\tau}=\bar{G}+(1-\beta) \bar{B}$.

To analyze the existence of equilibria near this steady state (3) can be linearized around the steady-state values, getting:

$$
\hat{b}_{t}=\beta^{-1}\left[\hat{b}_{t-1}-\bar{b} \pi_{t}-\bar{b} g+\hat{G}_{t}-\hat{\tau}_{t}\right]+\bar{b} \hat{i}_{t}
$$

where $\hat{b}_{t} \equiv\left(B_{t}-\bar{B}\right) / \bar{Y}, \hat{\tau}_{t} \equiv\left(\tau_{t}-\bar{\tau}\right) / \bar{Y}$ and $\hat{G}_{t}=\left(G_{t}-\bar{G} / \bar{Y}\right), \hat{i}_{t}=i_{t}-\bar{i}$ and $\bar{b} \equiv \bar{B} / \bar{Y}$. The term in steady-state growth in equation (9) comes from following a process similar to the derivation of (5) to get (6), by assuming a steady-state rate of growth $g$ of natural output $\overline{y_{t}}$. Such a growth is to be expected for an emerging market in the process of converging to world output levels. Steady state growth depends on the composition of fiscal policy, for example its contribution to expanding the infrastructure.

\footnotetext{
${ }^{3}$ The treatment in this section follows Woodford (2003), Chapter 4, Section 4.
} 
Woodford (2003, pp.312) defines a fiscal or tax rule as locally Ricardian if on substituting into the flow budget constraint (3) "it implies that $\left\{b_{t}\right\}$ remains forever within a bounded neighborhood of $\bar{B}$, for all paths of the endogenous variables $\left\{\pi_{\mathrm{t}}, \mathrm{Y}_{\mathrm{t}}\right.$, $\left.i_{t}\right\}$ that remain forever within some sufficiently small neighborhoods of the steady-state values $(0, \bar{Y}, \bar{i})$, and all small enough values of the exogenous disturbances (including $\left.\hat{G}_{t}\right) ”$

Under these circumstances the monetary policy rule and the outcomes of equilibrium inflation, output and interest rates do not depend on the paths of either of the purely fiscal variables $\left\{\mathrm{D}_{\mathrm{t}}, \tau_{\mathrm{t}}\right\}$ as they cancel out in the individual's budget constant. The fiscal policy rule can be neglected if it is Ricardian.

Suppose a linear approximation to the tax rule is of the form

$$
\hat{\tau}_{t}=\tau_{b} \hat{b}_{t-1}+\tau_{g} \hat{G}_{t}
$$

Substituting this into (9) gives the law of motion for real government debt as:

$$
\hat{b}_{t}=\beta^{-1}\left[\left(1-\tau_{b}\right) \hat{b}_{t-1}-\bar{b} \pi_{t}-\bar{b} g+\left(1-\tau_{g}\right) \hat{G}_{t}\right]+\bar{b} \hat{i}_{t}
$$

This implies tax rule (10) is locally Ricardian if and only if $\left|\beta^{-1}\left(1-\tau_{b}\right)\right|<1$.

If $\tau_{b} \leq 1$, then fiscal policy is locally Ricardian if and only if $\tau_{b}>1-\beta$.

Defining equilibrium "to be (locally) determinate if and only if there are unique bounded equilibrium processes for all of the endogenous variables $\left\{b_{t}, \pi_{t}, Y_{t}, i_{t}\right\}$ for sufficiently tightly bounded processes for the exogenous disturbances pp. (314)", Woodford (2003) shows that fiscal policy is locally Ricardian if and only if the response of monetary policy 
to inflation exceeds unity. If, however, fiscal policy is locally non-Ricardian, bounded paths for the endogenous variables will require monetary policy to violate the Taylor Principle. For example, if debt is unsustainable, it will require monetary accommodation.

Woodford, following earlier literature (see, for example, Davig and Leeper, 2009), then distinguishes between active and passive fiscal and monetary policies. If fiscal policy is Ricardian (passive) monetary policy can be active. If, however, fiscal policy is nonRicardian (active) monetary policy must become passive (accommodating) to prevent instability.

We explore some combinations of monetary and fiscal policy for an emerging market through simulations below.

\section{Simulations}

The central bank minimizes a quadratic loss function--weighted averages of domestic inflation, output and interest rate deviations from equilibrium values ( $\left.L=q_{Y} y^{2}+q_{\pi} \pi^{2}+q_{i} i^{2}\right)$ subject to the $\mathrm{AD}, \mathrm{AS}$, uncovered interest rate parity and the law of motion for real public debt. Dynamic impulse responses to cost, natural rate, and government expenditure shocks can be derived from the optimization ${ }^{4}$.

Calibration was loosely based on Indian stylized facts. Since empirical estimations and the dominance of administered pricing in SOEME's suggest that past inflation affects current inflation, the modification of the AS

$$
\pi_{H, t}=\gamma_{f} \beta E_{t}\left\{\pi_{H, t+1}\right\}+\kappa_{D} x_{t}+\gamma_{b} \pi_{H, t-1} \quad \gamma_{f}+\gamma_{b}=1
$$

was used, with the share of lagged prices $\gamma_{\mathrm{b}}$ set at 0.2 so $\gamma_{\mathrm{f}}$ was 0.8 . Because of less than perfectly flexible interest rates, lagged interest rate also enter the AD with a weight of 0.2 . The openness coefficient $\alpha$ is set at 0.3 ; the proportion of $R,{ }^{5} \eta$, at 0.4 . The natural

\footnotetext{
${ }^{4}$ The model was solved in state-space form by modifying Soderlind's Matlab algorithms available at http://home.tiscalinet.ch/paulsoderlind. Available on request.
} 
output $\bar{y}_{\mathrm{t}}$ is optimally equivalent to a flexible price equilibrium, if a subsidy is set so as to correct for market power, openness and other distortions. This is calibrated for emerging markets in Goyal (2009a) but is not required in the current simulations. The price setting parameters are such that prices adjust in an average of one year $(\theta=0.75)$, giving $\lambda=$ 0.24 . The price response to output, $\varphi$, is set at 0.25 , which implies an average labour supply elasticity of 4 .

Since $\sigma_{\mathrm{R}}=1$ and $1 / \sigma_{\mathrm{P}}=0$, the implied average intertemporal elasticity of substitution is $\eta(1-\alpha)+\alpha=0.58 ; \beta=0.99$ implies a riskless annual steady-state return of 4 percent; and the natural interest rate is kept fixed at $\rho=\beta^{-1}-1=0.01$. Consumption of the mature economy and of the rich is normalized at unity, five times that of the poor so $C_{P}=0.2$. Given $\eta$, this gives consistent $C$ values of $0.75, \mathrm{~K}$ (a measure of deviation from world output) of 1.1 so that $c_{P}=-1.6$ and $\mathrm{K}=0.1$. Initial conditions are normalized at unity so the $\log$ value is zero.

A negative interest rate effect on consumption requires an intertemporal elasticity large enough so that the substitution effect is higher than the positive income effect of higher interest rates on net savers. Empirical studies have found real interest rates to have weak effects on consumption. Especially in low-income countries, subsistence considerations are stronger than intertemporal factors. This is particularly so when the share of food in total expenditure is large. The elasticity Ogaki, Ostry and Reinhart (1996) estimate in a large cross-country study, varies from 0.05 for Uganda and Ethiopia to a high of 0.6 for Venezuela and Singapore. Our average elasticity compares well with these figures.

The weights attached to the arguments of the CB's loss function are set at 0.7, 2 and 1 respectively. The weight on inflation $q_{\pi}$ exceeding unity satisfies the Taylor principle. The fiscal variables follow average Indian ratios: since $\tau_{b}$ is taken as 0.15 the average current ratio of tax revenues to $\mathrm{D}, \tau_{g}$ is set at zero, $\bar{b}$ is 0.8 , and $\mathrm{g}$ is 0.006 for each simulation period. 
Cost shocks are frequent in SOEMEs, shocks to subsistence consumption imply a large shock to the natural rate, populist pressures affect government expenditure, $\hat{G}$. Therefore the exogenous driving forces simulated are period one calibrated 0.2 standard deviation cost shock to domestic inflation, 0.01 negative shock to the natural rate, and 0.1 standard deviation shock to government expenditure.

Table 1 reports some of the simulations done. The benchmark simulations give consumer inflation, output gap, domestic inflation, debt and the policy rate volatilities for each of the shocks. The initial values of $\hat{b}_{t}$ and $i_{t}$ are also reported. Figures 1 and 2 show the response of each of these variables to the cost and natural rate shock respectively over the 12 periods of the simulation. The deviations are from steady-state values. The table also reports sensitivity analysis with respect to the fiscal parameters and the weights of the CB's loss function while Figures 3, 4 show the response of $\hat{b}_{t}$ to the variation in each parameter for the cost and natural rate shock respectively. Figure 5 gives the response of $\hat{b}_{t}$ to $\hat{G}$ shocks of varying persistence.

\section{Place Table 1 and Figures 1-5 here}

There are interesting insights from the simulations. The inflation following the cost shock leads to a fall in $\hat{b}_{t}$, but it returns to its steady state value in 4 periods. If natural rates fall $\hat{b}_{t}$ rises sharply, to compensate for the fall in $\mathrm{c}_{\mathrm{P}}$. Convergence back to the steady state is slow, not fully completed in the 12 periods.

Sensitivity analysis for both types of shocks is similar. A fall in $\tau_{b}$ reduces the deviation from steady state, since adjustment back would be more difficult. If $\bar{b}$ is lower, current borrowing requirement is reduced, and $\hat{b}_{t}$ rises less. A change in $g$ is the only one to have different effects under the 2 types of shocks. Under a cost shock, higher growth reduces the deviation of debt but for a natural rate shock it increases it. This shock to the 
consumption of the poor induces the government to borrow more if growth is high, but contribution of debt to the adjustment process is reduced under a cost shock.

In accordance with Woodford's theoretical result, equilibrium does not exist if $q_{\pi}<1$, but under both shocks, if $q_{\pi}=1.1$ instead of 2 policy rates are lower. This monetary accommodation reduces the change in debt but increases deviations in the other macroeconomic variables. The table reports a simulation where all the weights in the CB's loss function are reduced to 0.5 and $\tau_{b}$ is put at zero. Equilibrium is determinate. The macroeconomic adjustment is of a similar order of magnitude as the case with $q_{\pi}=1.1$ as the only change, but the fall in $\tau_{b}$ reduces the debt deviation as earlier. If the only change from benchmark shock is $\tau_{b}=0$, equilibrium is determinate, the other macroeconomic variables are the same as in the benchmark shock, only the deviation in debt is considerably reduced.

Considering a calibrated 0.01 shock to $\hat{G}$ of persistence 0.25 the only effect is a temporary fall in debt. But equilibrium is indeterminate if persistence exceeds 0.9. With persistence of 0.85 equilibrium becomes determinate but unstable. Equilibrium is indeterminate if $q_{\pi}<1$, determinate but even more unstable than the benchmark $\hat{G}$ shock if $q_{\pi}=1.1$. The volatility of other macroeconomic variables is reduced if $\tau_{b}=0$ since the initial rise in debt is considerably reduced, but $\hat{b}_{t}$ continues to be unstable remaining far from steadystate values at the end of 12 periods. As in simulations with earlier variants of SOEME models (Goyal 2007), a rise in the share of the rich and in openness reduces initial interest and therefore debt response, for both types of shocks, implying greater debt volatility is to be expected in a poorer less globally integrated country ${ }^{6}$.

\section{Monetary-Fiscal Policy Combination}

Much more work needs to be done to explore the regions of determinacy and instability as a function of the parameters. The response to other types of shocks can also be

\footnotetext{
${ }^{6}$ Simulations not reported available on request
} 
explored. Results will change if debt or wealth enters the AD equation, and if the weights in the CB's loss function are optimally derived accounting for public debt. Annicchiarico et. al. (2008) find the region of determinacy rises in an overlapping generation model with wealth effects, raising the scope for active monetary policy. Wealth effects through the balance of payments are an important contributor to persistent effects of monetary policies in an open economy, but in a low per capita income economy taxes can be expected to neutralize wealth in order to smooth consumption of the P-type. Gali et. al. (2007) introduce rule-of-thumb consumers which then allows fiscal expenditure to raise their consumption and requires a stronger monetary response. But in our model, although the P-type are not forward looking, their consumption is fixed at subsistence, so that the neutralization of a fiscal stimuli through expected future taxes, and subject to greater rigidities in an EME, continues to be a valid first approximation. An EME typically has a large debt yet since it is in a transitional catch up phase, the borders between active and passive fiscal and monetary policy can differ, as we find. Davig and Leeper (2009) explore the consequences of the fiscal stimuli in a DSGE model with markov switching between different monetary and fiscal policies. More complex models will yield more insights but the key contribution of consumption shocks and growth in emerging markets will remain.

Taking lessons from the current simulations for the conduct and coordination of monetary and fiscal policy in an emerging market, under an optimization respecting the law of motion of public debt, debt should optimally rise in response to a shock to subsistence consumption, and the rise will be higher the higher is debt, and the higher is growth, but should be moderated if the tax response to a rise in debt is low. Higher growth moderates debt volatility under cost shocks. Monetary accommodation is useful to moderate the debt response under shocks but is dangerous if the shock is a persistent rise in government expenditure.

\section{Indian Macroeconomic Policy Options}

In this section we apply insights from the analysis to current Indian policy dilemmas. Despite high growth over 2003-08 and the adoption of an FRBM Act, Indian debt levels 
did not come down much. And despite low fiscal space the government gave large fiscal boosts over 2008-09. Does this imply a sustained rise in debt levels?

According to the analysis in the first section, high private savings, with a savings to GDP ratio exceeding 30, reduce the probability of a CAD and BOP crisis. Growth rates continue to be relatively high compared to most countries in the world, implying continuing capital inflows. Even if aggregate inflows are reduced India will get a higher share.

Next we turn to analysis of the evolution of Indian public debt, following the second section. Figure 1 shows the change in $b$ as a percentage of $b_{t-1}$. It also shows the two components of the change in debt from Equation (6), over the Indian post-reform period. The nominal interest rate calculated is the implicit rate the central government pays on its debt. It is obtained by dividing actual interest payments in the budget documents $i D$ by $D$. $D$ is also obtained from the budget documents ${ }^{7}$. Inflation calculated from the GDP deflator is subtracted from $i$, in order to get the real rate $r$. The growth rate used is the growth of real domestic product at market prices. Finally $b_{t-1}\left(r_{t}-g_{t}\right)$ and $p d$ are graphed. The figure shows that $r$ was normally less than g over this period and since this negative value exceeded a mostly positive $p d, b$ should have fallen much more than it did. The discrepancy is particularly acute in the high growth period after 2003, since the $p d$ was also falling over this period. Given the fall in $b$ that should have occurred due to $r$ and $g$, actual $b$ did not fall; implying deficits must have been higher. Reported deficits may have been doctored, to satisfy the FRBM targets ${ }^{8}$ applicable in this period. Government debt also increased through off balance sheet items.

\footnotetext{
${ }^{7}$ Data for the period $1990-91$ to $2007-08$ is graphed. Calculations, available on request, were made from data available from ministry of finance and RBI websites. Debt and deficit figures are for the Central Government.

${ }^{8}$ This was enacted by Parliament in 2003. The Rules accompanying the FRBM Act required the Centre to reduce the fiscal deficit to 3 per cent of GDP and, eliminate revenue deficit by March 31, 2008. There is also a ceiling on guarantees. But the ceilings may be exceeded during "national security or national calamity or such other exceptional grounds as the Central Government may specify", so that the Government can legislate itself out of the commitments. In addition the budget has to each year place before Parliament the Medium Term Fiscal Policy, Fiscal Policy Strategy and Macroeconomic Framework statements. Deficit financing or money creation is banned, but there are no restrictions on OMOs. Any deviations require the permission of Parliament.
} 
Figure 2 shows the movements in the relevant rates over the period. Although nominal interest rates were higher in the earlier years the consistent fall in inflation rates over the period meant the real interest rates on government debt rose from early strongly negative rates, to peak at 5 percent in 2000-01 before beginning to fall as nominal rates also fell. Since real rates were low in both the high growth phases $r$ - $g$ was strongly negative in high growth periods. The reported $p d$ is also lower in high growth periods. In the second period revenues were high - the tax GDP ratio peaked at 11.5 percent. But the fall in $b$ was larger in the briefer high growth period of the mid-nineties.

\section{Place Figures 6, 7 here}

For the first time, pd turned into a surplus in 2004-05, but it had increased to 2.5 in 2008 09, the year of the global financial crisis, and was projected to be even higher at 3 percent in the next year. For the debt ratio to stay unchanged at around 0.8 , at the current PD ratio, the growth rate must exceed the real interest rate by 3.75 basis points.

At current rates the government debt ratio will increase. Using figures from the budget estimates for 2009-10. The $P D$ ratio was $3, \mathrm{r}=4, \mathrm{~g}=7$. Our formula implies that in the steady-state when $b$ is not changing, $\mathrm{b}=\mathrm{PD} / \mathrm{g}-\mathrm{r}=100$ percent. Unless growth revives and the $p d$ is reduced India's steady-state debt is much higher than current levels. If the reverse happens debt can explode. Since even high growth together with the FRBM was insufficient to reduce India's debt suggests that a better conceived FRBM that improves incentives for compliance is required.

Growth did reduce debt levels, but the desire to protect the consumption of the aam admi seems to have moderated the reduction in the second high growth period. Since the global shock reduced employment and $c_{\mathrm{P}}$ the SOEME simulations suggest debt and deficit levels can be expected to rise after the shocks, they will be higher the higher are $b$ levels and growth. Monetary accommodation can help reduce $b$ to the extent soft commodity prices reduce inflation and the rise in $\mathrm{G}$ is temporary. It is very important that there is no 
permanent rise in $\mathrm{G}$ in excess of taxing capacity. The excise cuts given as part of the post-crisis fiscal stimuli can be reversed, the Pay Commission arrears and farm loan waivers are one-time payments, but new recurring expenditure commitments must be made only on a secure tax base.

A distinction should be made between structural and cyclical deficits. At the present juncture, with private demand slowing, a cyclical deficit is needed. A structural deficit may also be defended in a transitional high growth period, since growth reduces debt ratios. But the level of debt and deficits should be reduced in good times in order to create space for countercyclical fiscal policy. The inability to bring down debt levels in the high growth period suggests that other measures are required to ensure medium-term fiscal consolidation. We discuss these in order of importance.

The FRBM Act, brought down only reported deficits, which were on track to meet announced targets before the oil shock hit. But the episode exposed the inadequate attention paid to incentives and escape clauses in formulating the Act. Loopholes were found to maintain the letter of the law even while violating its spirit. Off balance sheet items such as oil bonds were used to subsidize some petroleum products. Targets were mechanically achieved, compressing essential expenditure on infrastructure, health and education, while maintaining populist subsidies. The Act should be reframed to improve incentives for compliance. Expenditure caps that bite especially on transfers, while protecting productive expenditure, will create automatic counter-cyclical stabilization as tax revenue falls and deficits rise in a slowdown. Productive expenditure is anything that improves human, social, and physical capital. Change in the composition of government expenditure towards increasing growth will bring down debt ratios, by increasing the denominator of the ratio. Essential transfers must be better targeted to reduce waste.

A more credible FRBM will allow better fiscal-monetary coordination make monetary accommodation during the crisis period safe. To use Woodford's terminology, a passive monetary policy can accompany an active fiscal policy during the crisis, as long as they switch positions in the longer term. The more usual recent combination in India is for 
both to be active, which has harmed growth, as monetary tightening sought to compensate for fiscal giveaways. When Indian interest rates fell after 2000, despite high government deficits, and aggressive sterilization, because international interest rates fell, growth was stimulated.

In the post-crisis circumstances, despite high government borrowing due to the fiscal stimuli, lower inflows give the RBI leeway to increase the share of government securities in the monetary base. This helps finance the deficit and limits crowding out of reviving private borrowing. In addition to cuts in policy rates, quantitative easing with OMOs through the term structure can ease pressure on interest rates.

As the composition of fiscal expenditure changes, monetary policies can also be recast to support growth, and further boost the diversified sources that sustain Indian growth. These include domestic demand, agriculture, openness, technology, the demographic profile, the infrastructure cycle, and having crossed a critical threshold. As a net commodity importer India gains from lower global prices. Dependence on external demand is low compared to other Asian countries. So is the dependence on foreign capital. But although aggregate savings are high, about half of household savings are in physical form, making it difficult to finance high government and reviving private borrowing. Slowdown in foreign funds may force development of the corporate bond market, and require RBI backing of credit to SMEs to better intermediate savings and raise India's low credit/GDP ratio.

Lower tax response has a disciplining effect on debt expansion. But more efficient systems of tax collection will decrease debt if a more effective FRBM restrains the government. India does have improved technology-based tax systems, independent of government, that have delivered on the first, and more improvements such as GST are on the way. There has been steady lowering of tax rates. Technology has been used to broaden coverage, and reduce loopholes. The experience with the destination based State level VAT since 2005 has been good. The proposed move to GST in 2010 should yield large efficiency gains of one market. Continuing growth may protect some of the recent 
buoyancy in tax revenue but revenue expansion due to improved compliance and broad basing will survive a slowdown. Indian fiscal policy has made considerable progress in tax reform, but improvements in expenditure management are yet to come. Even so there was a steady increase in the quality of Indian institutions.

Therefore because of improvements in tax collection, and trends in growth and real interest rates, with better incentives from the FRBM Act, Indian debt ratios are unlikely to become unsustainable, despite the fiscal boost. Just as Indian savings rates are rising to Chinese levels, Indian fiscal health can also approach Chinese levels if growth is sustained. Chinese government debt and deficits had peaked in the years of their big infrastructure push starting in the late nineties, but debt began to come down after 2005 . China as another populous emerging market, benefited from policies that harvested the growth dividend on deficits and debt.

\section{References:}

Annicchiarico B., G. Marini and A. Piergallini. 2008. Monetary Policy and Fiscal Rules. The B.E. Journal of Macroeconomics; 8(1) (Contributions), Article 4, 1-40

Clarida R., Gali J., and Gertler M. 1999. The Science of Monetary Policy: A New Keynesian perspective. Journal of Economic Literature ; 37 (4), 1661-707.

Clarida R., Gali J., and Gertler M. 2001. Optimal Monetary Policy in Closed Versus Open Economies: An integrated approach. American Economic Review; 91 (2); May; 248-252.

Gali J. and T. Monacelli. 2005. Monetary Policy and Exchange Rate Volatility in a Small Open Economy. Review of Economic Studies; 72(3): 707-734. Earlier circulated as July 27, 2004 working paper.

Gali J., J. David Lopez-Salido and J. Valles. 2007. Understanding the Effects of Government Spending on Consumption. Journal of the European Economic Association; 5(1): 227-270.

Goyal A. 2007. A General Equilibrium Open Economy Model for Emerging Markets. Paper presented at ISI International Conference on Comparative Development, available at http://www.isid.ac.in/ planning/ComparativeDevelopmentConference.html. An earlier version is available as IGIDR working paper WP-2007-016. 
Goyal A. 2009a. The Natural Interest Rate in Emerging Markets. In Bhaskar Dutta, Tridip Roy, and E. Somanathan (Eds.), New and Enduring Themes in Development Economics, World Scientific Publishers, forthcoming. Earlier version available as IGIDR working paper at www.igidr.ac.in/pdf/publication/WP-2008-014.pdf.

Goyal A. 2009b. The Structure of Inflation, Information and Labour Markets: Implications for Monetary Policy. Pradeep Agrawal, Biswanath Goldar and Pulin Nayak (eds.), New Delhi: Sage, forthcoming. Earlier version available as IGIDR working paper at www.igidr.ac.in/pdf/publication/WP-2008-010.pdf.

Davig, T. and E.M. Leeper. 2009. Monetary Fiscal Policy Interactions and Fiscal Stimulus, NBER working paper, 15133.

Ogaki, Masao, Jonathan Ostry, and Carmen M. Reinhart. Savings Behaviour in Low-and Middle-Income Countries: A comparison. IMF Staff Papers 43 1996; 38-71; March

Woodford, M. Interest and Prices: Foundations of a Theory of Monetary Policy. NJ: Princeton University Press. 2003

\section{Appendix}

\section{Optimization in the SOEME model}

Consumers and workers

A typical SOEME has two representative households: above subsistence (R) and at subsistence $(\mathrm{P})$. The intertemporal elasticity of consumption $\left(1 / \sigma_{R}\right)$, productivity and wages $\left(W_{R}\right)$ of $R$ are higher, their labour supply elasticity $\left(1 / \varphi_{R}\right)$ is lower compared to the $\mathrm{P}$, and they are able to fully diversify risk in international capital markets. Each type seeks to maximize the discounted present value of utility - a positive function of consumption and a negative function of labor supplied:

$$
E_{o} \sum_{t=0}^{\infty} \beta^{t} U\left(C_{i, t}, N_{i, t}\right) \quad \mathrm{i}=\mathrm{R}, \mathrm{P}
$$

$\mathrm{N}_{\mathrm{i}, \mathrm{t}}$ denotes hours of labor supplied by each type. Aggregate consumption $\mathrm{C}_{\mathrm{t}}$ is a composite index of consumption of home $(\mathrm{H})$ and foreign goods $(\mathrm{F})$. Elasticity of substitution between $\mathrm{H}$ and $\mathrm{F}$ goods is assumed to equal unity. In this case the CES aggregation simplifies to (A2) for consumption and (A3) for the price index. Each of $\mathrm{C}_{\mathrm{H}}$, t, $\mathrm{C}_{\mathrm{F}, \mathrm{t}}$ are indices of a continuum of differentiated home and foreign goods respectively with elasticity of substitution between goods of different varieties, $\varepsilon>1$, as is required for 
equilibrium under monopolistic competition. Simplifications are made to reduce the degree of disaggregation, and focus on disaggregation of consumption between the $\mathrm{R}$ and the P households ${ }^{9}$.

The corresponding consumer price index can be derived from cost minimization of the consumption bundle as is standard in the literature. The share of foreign goods, $\alpha, 0<$ $\alpha<1$, defines the degree of openness. It is inversely related to the degree of home bias, and is assumed to be the same for R and P, since although P spend more on food, agricultural products are also traded goods.

$$
C_{t} \equiv k C_{H, t}^{1-\alpha} C_{F, t}^{\alpha}
$$

Given the constant $k=\frac{1}{(1-\alpha)^{1-\alpha} \alpha^{\alpha}}$, the price index can be written as:

$$
P_{t}=P_{H, t}^{1-\alpha} P_{F, t}^{\alpha}
$$

Since the effective terms of trade, or price of foreign goods in terms of home goods, is $S_{t}=P_{F, t} / P_{H, t}$, substituting in (A3) gives:

$$
P_{t}=P_{H, t} S_{t}^{\alpha}
$$

That is, consumer prices depend on domestic prices and the terms of trade.

Consumption of each type of good is a weighted average of consumption by the $\mathrm{R}$ and the P households, with $\eta$ as the share of R. Since R and P consume H and F in the same proportion, $\mathrm{C}_{t}$ is distributed between $\mathrm{R}$ and $\mathrm{P}$ in the same proportion $\eta$, where $\eta$ is the share of above subsistence households in consumption.

$$
\begin{aligned}
& C_{H, t}=C_{P, t}^{1-\eta} C_{R, t}^{\eta} \\
& C_{F, t}=C_{P, t}^{1-\eta} C_{R, t}^{\eta} \\
& C_{t}=k\left(C_{P, H, t}^{1-\alpha} C_{P, F, t}^{\alpha}\right)^{1-\eta}\left(C_{R, H, t}^{1-\alpha} C_{R, F, t}^{\alpha}\right)^{\eta}
\end{aligned}
$$

A household's period utility function is given the specific form: 


$$
U\left(C_{i}, N_{i}\right) \equiv \frac{C_{i, t}^{1-\sigma_{i}}}{1-\sigma_{i}}-\frac{N_{i, t}^{1+\varphi_{i}}}{1+\varphi_{i}} \quad \mathrm{i}=\mathrm{R}, \mathrm{P}
$$

The constant relative risk aversion (CRRA) utility function is defined for $\sigma$ greater than zero and not equal to unity. At $\sigma$ equal to unity it becomes $\ln C$. Utility is maximized subject to a sequence of period budget constraints:

$$
P_{t} C_{i, t}+E_{t}\left\{Q_{t, t+1} D_{i, t+1}\right\} \leq D_{i, t}+W_{i, t} N_{i, t}-T_{i, t}
$$

Where $\mathrm{W}_{\mathrm{i}, \mathrm{t}}$ is the nominal wage paid to each type, $\mathrm{Q}_{\mathrm{t}, \mathrm{t}+1}$ is the stochastic discount factor corresponding to the random payoff $\mathrm{D}_{\mathrm{t}+1}$ of the portfolio purchased at $t ; \mathrm{I}_{\mathrm{t}}$ is the gross nominal yield on a riskless one period discount bond, paying one unit of domestic currency in $\mathrm{t}+1$, so that $I_{t}^{-1}=E_{t}\left\{Q_{t, t+1}\right\}$ is the price of the discounted bond; $\mathrm{T}_{\mathrm{i}, \mathrm{t}}$ is lump sum taxes or transfers. Taxes $T_{R, t}$ from $R$ partly finance transfers $T_{P, t}$ to $P$; since the latter have zero savings $\mathrm{D}_{\mathrm{P}}$ is zero. The government intermediates these transfers. The government also gets revenue from its international assets, net of any cost of accumulating foreign exchange reserves. The subsidy is calculated to give $\mathrm{P}$ a subsistence wage if they work eight hours daily, but they are free to increase their wages by working longer hours. Under these conditions fiscal variables drop out and do not affect individual decisions (Woodford, 2003). The economy is assumed to be cashless so monetary policy works by changing interest rates.

Capital markets are complete, but only the R-type of consumers can participate in them. Since P lack the ability to smooth consumption their intertemporal elasticity of consumption approaches zero. This allows us to define the aggregate intertemporal elasticity of substitution, $1 / \sigma$. This and the inverse of the labour supply elasticity, $\varphi$, are weighted sums with population shares of $\mathrm{R}$ and $\mathrm{P}$ as weights,

$$
\begin{aligned}
& \frac{1}{\sigma}=\eta \frac{1}{\sigma_{R}}+(1-\eta) \frac{1}{\sigma_{P}} \\
& \varphi=\eta \varphi_{R}+(1-\eta) \varphi_{P}
\end{aligned}
$$

Since $\sigma$ is the coefficient of relative risk aversion, an intertemporal elasticity of consumption approaching zero implies risk aversion approaching infinity for the poor. 
The standard first order conditions for optimal allocation of consumption across home and foreign goods yield the demand functions:

$$
\begin{aligned}
& P_{H, t} C_{H, t}=(1-\alpha) P_{t} C_{t} \\
& P_{F, t} C_{F, t}=\alpha P_{t} C_{t}
\end{aligned}
$$

And from intertemporal optimization, for $\mathrm{i}=\mathrm{R}$, we must have:

$$
\beta\left(C_{i, t+1} / C_{i, t}\right)^{-\sigma_{i}}\left(P_{t} / P_{t+1}\right)=Q_{t, t+1}
$$

Then taking expectations on both sides of (A11) gives the consumption Euler equation:

$$
\beta R_{t} E_{t}\left\{\left(C_{i t+1} / C_{i t}\right)^{-\sigma}\left(P_{t} / P_{t+1}\right)\right\}=1 \quad \text { for } \mathrm{i}=\mathrm{R}
$$

The $i$ th household's labour supply is given by:

$$
C_{i, t}^{\sigma_{i}} N_{i, t}^{\varphi_{i}}=\frac{W_{i, t}}{P_{t}} \quad \mathrm{i}=\mathrm{R}, \mathrm{P}
$$

Since $C_{P}$ is subsidized to prevent it falling below subsistence, we must have $T_{P, t}=C_{P, t}$ $\mathrm{W}_{\mathrm{P}, \mathrm{t}} \mathrm{N}_{\mathrm{P}, \mathrm{t}}$. Equations (A12) and (A13) can be written in log linear form as:

$$
\begin{gathered}
w_{i, t}-p_{t}=\sigma_{i} c_{i, t}+\varphi_{i} n_{i, t} \\
c_{i, t}=E_{t}\left\{c_{i, t+1}\right\}-\frac{1}{\sigma_{i}}\left(i_{t}-E_{t}\left\{\pi_{t+1}\right\}-\rho\right) \quad \mathrm{i}=\mathrm{R}
\end{gathered}
$$

Although $c_{P}$ is exogenously given it can rise with a rise in subsistence levels. Lower case letters are logs of the respective variables; $\rho \equiv \beta^{-1}-1$ is the time discount rate, and $\pi_{t} \equiv p_{t}-p_{t-1}$ is CPI (consumer price index) inflation (with $\mathrm{p}_{\mathrm{t}} \equiv \log \mathrm{P}_{\mathrm{t}}$ ).

To solve for $S_{t}$ in terms of endogenous $Y_{t}$ and exogenous variables, first substitute $C_{R, t}$ and $C_{P, t}$ for $C_{t}$ in the aggregate demand equal to supply equation and then substitute out $\mathrm{C}_{\mathrm{R}, \mathrm{t}}$ using risk smoothing. This gives:

$$
S_{t}=\left(\frac{Y_{t}}{Y_{t}^{* \eta} C_{P, t}^{1-\eta}}\right) \sigma_{D}
$$

The terms of trade depreciate with a rise in $\mathrm{Y}_{\mathrm{t}}$ and appreciate with a rise in $\mathrm{Y}_{\mathrm{t}}{ }^{*}$; but in a SOEME the former's effect is magnified. $C_{P, t}$ also affects $S_{t}$, reducing the impact of $Y_{t}{ }^{*}$. The multiplier factor $\sigma_{\mathrm{D}}$, which affects only the SOEME, is large because the elasticity of substitution is lower for a SOEME. If $\sigma_{R}=1$, then $\varpi=1$, and if $1 / \sigma_{P}=0$, then $\sigma=\sigma_{R} / \eta$. It 
also follows that $\sigma_{\mathrm{D}}<\sigma$. Both rise as $\eta$ falls or the proportion of $\mathrm{P}$ with low intertemporal elasticity of consumption $\left(1 / \sigma_{\mathrm{P}}=0\right)$ rises. While $\eta$ affects $\sigma$, both $\eta$ and $\alpha$ affect $\sigma_{D}$. As $\alpha$ falls $\sigma_{\mathrm{D}}$ rises, and as $\alpha$ approaches 0 , or the economy becomes closed, $\sigma_{\mathrm{D}}$ equals $\sigma$, which is its upper bound. In a fully open economy $\alpha$ approaches unity, and $\sigma_{\mathrm{D}}$ falls to its lower bound, which is unity.

Equating consumption Euler equations for the R consumer in the SOEME and consumers in a mature economy denoted by superscript $i$, integrating over all $i$ to get average world consumption $\mathrm{C}^{*}$, using it and the definition of the real exchange rate $\mathrm{Z}$, risk sharing gives:

$$
C_{R, t}=v C_{t}^{*} Z_{t}^{\frac{1}{\sigma_{R}}}
$$

\section{Firms}

A typical firm has a log-linear production technology, derived by aggregation over the individual firms producing the $j$ differentiated goods. It is written in log terms as:

$$
y_{t}=a_{t}+n_{t}
$$

Where $N_{t}=N_{P, t}^{1-\eta} N_{R, t}^{\eta}$ aggregates over the two types of labor in the economy and productivity $a_{t} \equiv \log \mathrm{A}_{\mathrm{t}}$ follows an AR (A1) process:

$$
a_{t}=\rho_{a} a_{t+1}+\varepsilon_{t}
$$

The real marginal cost in domestic prices, $\mathrm{mc}_{\mathrm{t}}$, is common across firms, as labor is mobile at the prevailing factor prices:

$$
m c_{t}=-v-a_{t}+\eta\left(w_{R, t}-p_{H, t}\right)+(1-\eta)\left(w_{P, t}-p_{H, t}\right)
$$

Where $\mathrm{mc}_{\mathrm{t}}$ is the sum of real wages in terms of domestic prices paid to $\mathrm{R}$ and to $\mathrm{P}$ minus the aggregate productivity shock and $v \equiv-\log (1-\tau)$ where $\tau$ can be understood as an employment subsidy paid to firms to counter market power, and other distortions due to terms of trade and the labor market, thus increasing their employment level to the optimal 
flexible price level. Substituting the wedge between domestic and consumer prices (A19) becomes:

$$
m c_{t}=-v+\eta\left(w_{R, t}-p_{t}\right)+(1-\eta)\left(w_{P, t}-p_{t}\right)+\left(p_{t}-p_{H, t}\right)-a_{t}
$$

Substituting from the consumers' optimizing labour-leisure decision (A14), and from the $\log$ version of (A4) for the terms of trade:

$$
m c_{t}=-v+\eta\left(\sigma_{R} c_{R, t}+\varphi_{R} n_{R, t}\right)+(1-\eta)\left(\sigma_{P} c_{P, t}+\varphi_{P} n_{P, t}\right)+\alpha s_{t}-a_{t}
$$

Thus $\mathrm{s}_{\mathrm{t}}$ affects marginal cost since foreign prices affect domestic prices and costs. Using the identities (A8) and (A22) below,

$$
\begin{aligned}
& \eta c_{R, t}+(1-\eta) c_{P, t}=c_{t} \\
& \eta n_{R, t}+(1-\eta) n_{P, t}=n_{t}
\end{aligned}
$$

$\mathrm{mc}_{\mathrm{t}}$ can be written as:

$$
m c_{t}=-v+\sigma c_{t}+\varphi n_{t}+\alpha s_{t}-a_{t}
$$

Using risk sharing to eliminate $\mathrm{c}_{\mathrm{t}}$, the production function (A17) to eliminate $n$, and the approximation $1 / \sigma_{\mathrm{P}}=0$, so $\sigma=\sigma_{\mathrm{R}} / \eta$, the marginal cost can be written as a function of domestic output and terms relating to the external sector.

$$
m c_{t}=-v+\sigma \eta y_{t}^{*}+\varphi y_{t}+\sigma(1-\eta) c_{P, t}-(1+\varphi) a_{t}+s_{t}
$$

The equivalent relationship for a mature economy (GM (2005)) is:

$$
m c_{t}=-v+\sigma y_{t}^{*}+\varphi y_{t}+s_{t}-(1+\varphi) a_{t}
$$

Given marginal cost, prices are set according to the Calvo staggered pricing model, generating the dynamics of inflation and therefore the aggregate supply. 


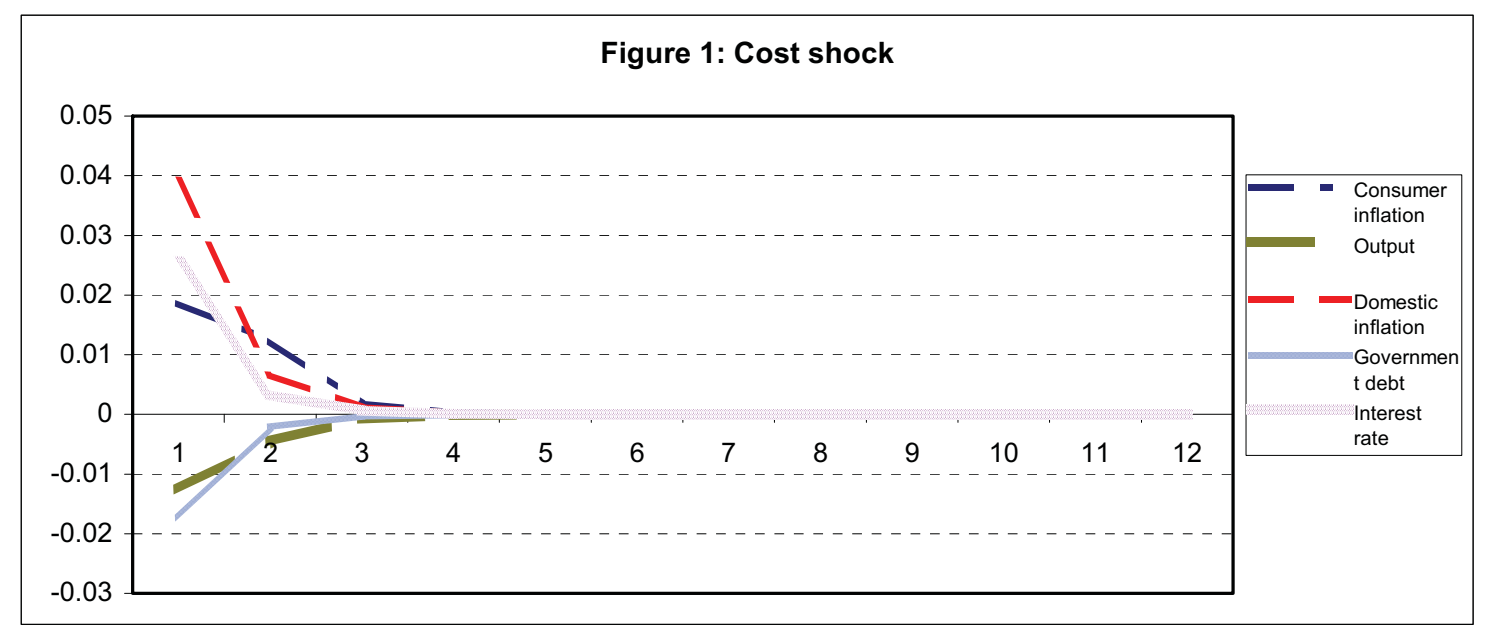

Figure 2: Natural rate shock

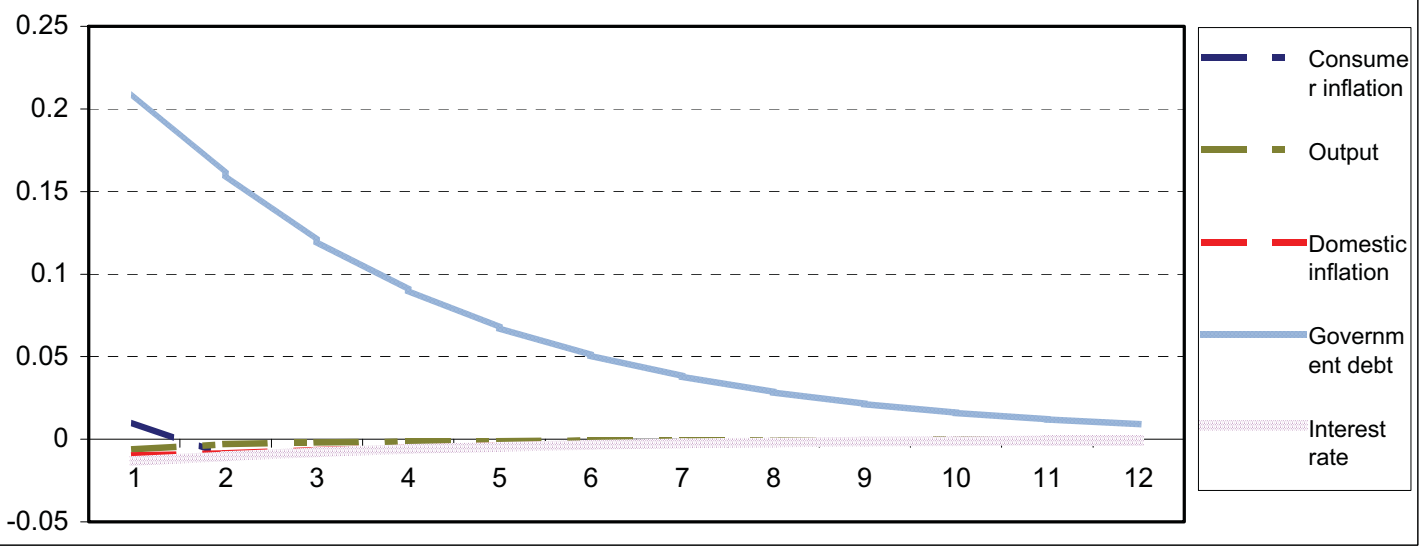

Figure 3: Debt response to cost shock

$\left.\begin{array}{r}-0.002 \\ -0.004 \\ -0.006 \\ -0.008 \\ -0.01 \\ -0.012 \\ -0.014 \\ -0.016 \\ -0.018 \\ -0.02\end{array}\right]$



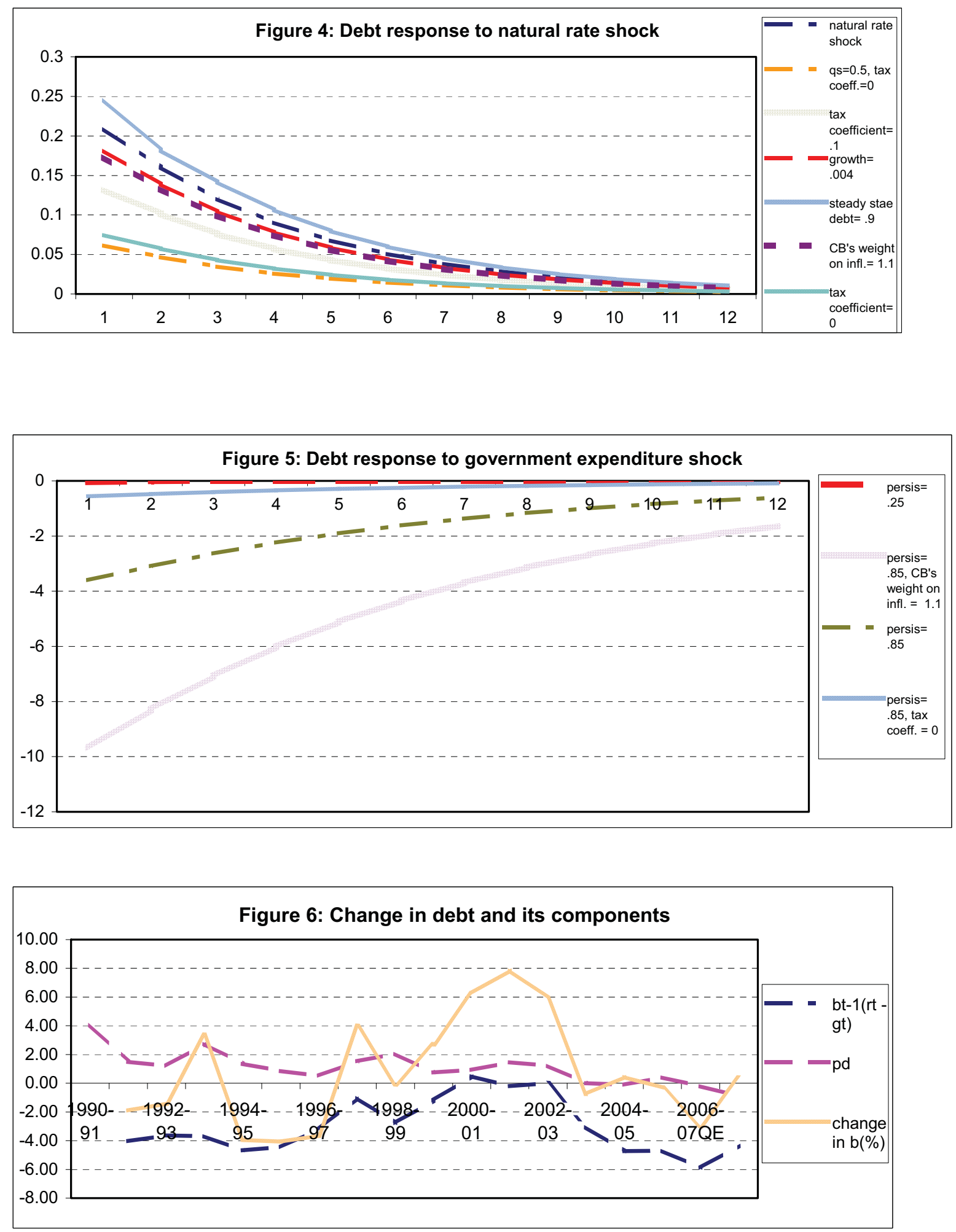


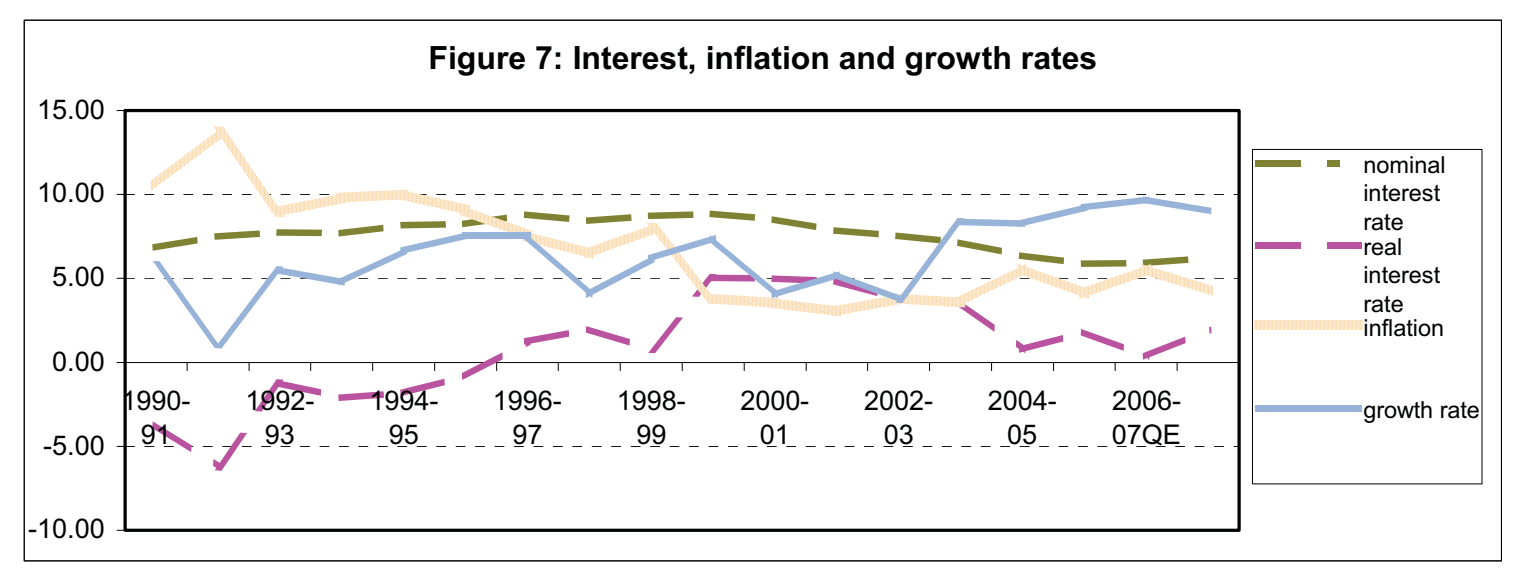

\begin{tabular}{|c|c|c|c|c|c|c|}
\hline \multicolumn{7}{|c|}{ Table 1: Simulations and volatilities } \\
\hline \multirow[t]{2}{*}{ Simulations } & Parameters & \multicolumn{5}{|c|}{ Standard deviations of (in percentages): } \\
\hline & $\bar{b}=0.8, \tau_{b}=0.15, g=0.006$ & $\begin{array}{l}\text { Consumer } \\
\text { inflation }\end{array}$ & Output & $\begin{array}{l}\text { Domestic } \\
\text { inflation }\end{array}$ & $\begin{array}{l}\text { Government } \\
\text { debt (initial } \\
\text { response) }\end{array}$ & $\begin{array}{l}\text { Interest rate } \\
\text { (initial } \\
\text { response) } \\
\end{array}$ \\
\hline \multirow[t]{5}{*}{ Cost shock } & Benchmark & 0.58 & 0.36 & 1.08 & $\begin{array}{l}0.48(- \\
0.0174)\end{array}$ & $0.70(0.0256)$ \\
\hline & $\tau_{\mathrm{b}}=0.1$ & 0.58 & 0.36 & 1.08 & $\begin{array}{l}0.45(- \\
0.0162) \\
\end{array}$ & $0.70(0.0256)$ \\
\hline & $\mathrm{g}=0.008$ & 0.58 & 0.36 & 1.08 & $\begin{array}{l}0.47(- \\
0.0169) \\
\end{array}$ & $0.70(0.0256)$ \\
\hline & $\bar{b}=0.7$ & 0.58 & 0.36 & 1.08 & $\begin{array}{l}0.42(- \\
0.0151) \\
\end{array}$ & $0.70(0.0256)$ \\
\hline & $\mathrm{q}_{\pi}=1.1$ & 0.71 & 0.18 & 1.21 & $0.16(0.0056)$ & $0.50(0.0181)$ \\
\hline \multirow{7}{*}{$\begin{array}{l}\text { Natural rate } \\
\text { shock }\end{array}$} & Benchmark & 0.47 & 0.16 & 0.31 & $6.18(0.2088)$ & $0.39(-0.0133)$ \\
\hline & $\tau_{\mathrm{b}}=0.1$ & 0.47 & 0.16 & 0.31 & $3.90(0.1319)$ & $0.39(-0.0133)$ \\
\hline & $\tau_{\mathrm{b}}=0$ & 0.47 & 0.16 & 0.31 & $2.20(0.0745)$ & $0.39(-0.0133)$ \\
\hline & $\mathrm{g}=0.004$ & 0.47 & 0.16 & 0.31 & $5.36(0.1813)$ & $0.39(-0.0133)$ \\
\hline & $\bar{b}=0.9$ & 0.47 & 0.16 & 0.31 & $7.27(0.2456)$ & $0.39(-0.0133)$ \\
\hline & $\mathrm{q}_{\pi}=1.1$ & 1.04 & 0.46 & 0.97 & $5.12(0.1730)$ & $0.83(-0.0279)$ \\
\hline & $\mathrm{qs}=0.5, \tau_{\mathrm{b}}=0$ & 1.01 & 0.42 & 0.91 & $1.81(0.0614)$ & $0.82(-0.0276)$ \\
\hline \multirow[t]{4}{*}{$\hat{G}$ shock } & Persistence $=0.25$ & 0.00 & 0.01 & 0.00 & $\begin{array}{l}1.14 \\
(-0.0412)\end{array}$ & $0.00(0.0000)$ \\
\hline & Persistence $=0.85, \mathrm{q}_{\pi}=1.1$ & 80.07 & 14.40 & 42.38 & $\begin{array}{l}251.63 \\
(-9.6890)\end{array}$ & $\begin{array}{l}37.48(- \\
1.4167)\end{array}$ \\
\hline & Persistence $=0.85$ & 87.47 & 08.67 & 28.19 & $\begin{array}{l}935.66 \\
(-3.5970)\end{array}$ & $\begin{array}{l}37.65(- \\
0.1389)\end{array}$ \\
\hline & Persistence $=0.85, \tau_{\mathrm{b}}=0$ & 01.15 & 0.12 & 0.42 & $\begin{array}{l}14.43 \\
(-0.5551)\end{array}$ & $0.56(-0.0204)$ \\
\hline
\end{tabular}

